\title{
A competency framework for coaches working in coaching development centres
}

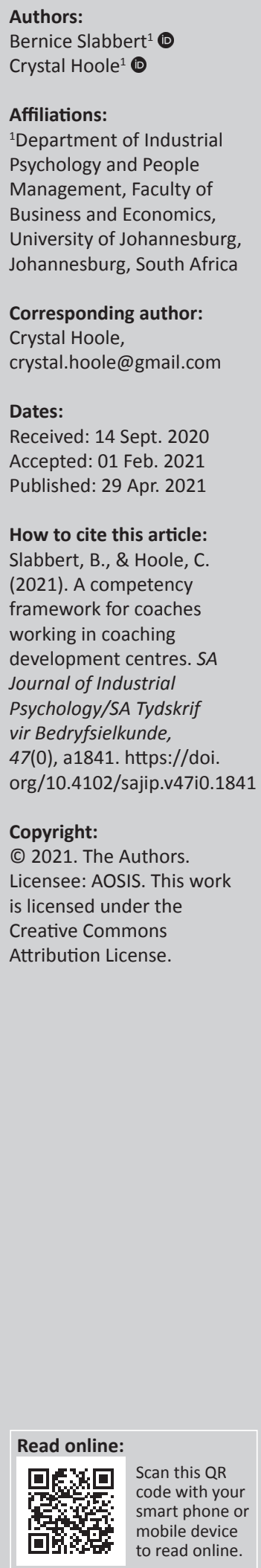

Authors:

Affiliations:

${ }^{1}$ Department of Industrial Psychology and People Business and Economics, University of Johannesburg,

author:

Crystal Hoole,

Dates:

Accepted: 01 Feb. 2021

How to cite this article: Slabbert, B., \& Hoole, C. development centres. $S A$ Journal of Industrial Psychology/SA Tydskrif 47(0), a1841. https://do

Copyright: Licensee: AOSIS. This work is licensed under the Creative Commons Attribution License.
Orientation: Globalisation and the new world of work has changed the labour market, resulting in highly complex, volatile and dynamic environments. Organisations are dependent on highly skilled human capital to not only survive but also thrive. Selecting and developing talent is thus becoming a business necessity. Assessment centres (ACs) and development assessment centres (DACs) have become popular tools to manage talent because of the successful outcomes it provides. In recent years, there has been a noticeable increase in the awareness of the benefits that coaching can offer in the AC environment as well as the development of coaching development centres (CDCs). However, research on CDCs is still limited. For CDCs to provide the same rigorous results as ACs and ADCs, a well-defined competency framework is needed for coaches working in a CDC.

Research purpose: The aim of this study was to explore the required competencies and formulate a competency framework for coaches working in a CDC.

Motivation for the study: Coaching, which is at the heart of coaching practices such as executive coaching, one-on-one coaching, team coaching and CDCs, requires a clear set of coaching competencies to ensure that it deliver its mandate to its clients: individuals, organisations and the profession. Coaches in a CDC environment work in a different context and require different competencies. A competency framework for CDC specifically is therefore needed.

Research approach/design and method: Adopting a qualitative methodology, a self-completed questionnaire was administered to eight participants, followed by a semi-structured interview. Lastly, the competency framework was verified by an expert panel of five experts using the Delphi technique.

Main findings: A final competency framework consisting of 25 competencies, of which 14 are considered as core competencies, was validated.

Practical/managerial implications: The study contributes to the understanding of the unique behavioural demands associated with coaches operating in the context of a CDC. It provides a conceptual and practical framework of what competencies are needed to work successfully and effectively as a coach in a CDC, and ultimately enhance the effectiveness of a CDC.

Contribution/value-add: Utilising this framework in practice will enable us to use candidates best suited to the role of a coach at a CDC, and will enhance the overall success of such centres.

Keywords: coaching; competency frameworks; coaching development centres; assessment centres; development assessment centres.

\section{Introduction}

Coaching, which is at the heart of coaching practices such as executive coaching, one-on-one coaching, team coaching and coaching development centres (CDCs), requires a clear set of coaching competencies to ensure that it deliver its mandate to its clients, individuals, organisations and the profession. One of the more recent developments in coaching, development assessment centres (DACs) and CDCs focuses specifically on value-added services to employers to help employees actualise their full potential (ACSG, 2015; Lievens \& Thornton, 2005; Rupp et al., 2006). Coaching competencies are therefore becoming more important than ever.

Coaching development centres have become increasingly popular in practice as tools in facilitating behavioural change and improving performance (ACSG, 2015; Lievens \& Thornton, 2005; Rupp et al., 2006). Coaches working in CDCs have a strong development focus by concentrating on improving participants' performance through coaching efforts. In CDCs, participants engage in a series of simulations which provide useful information on participants' 
strengths and development areas. The coach focuses specifically on job-related behaviours. The coach debriefs the participants after each simulation and participants can interactively share their simulation experience. The aim of these sessions is to align the participants' performance with the intended outcomes. The coach assists with the design of a customised development plan for the participant. Also unique to CDCs, a coach is allocated to each participant. An additional factor that needs to be taken into consideration is that these CDC coaches work under very tight timelines, which makes effective performance challenging (Lemasa, 2016). Improved performance will always be contextual and can be seen through the success of an individual's efforts in fulfilling specific tasks (Bartram, 2006; Campion \& Ployhart, 2013; Theron, 2014). This implies that coaches will require additional competencies to fulfil this role effectively.

Despite CDCs' growing popularity, limited research exists in this field. For instance, Yates (2015a) reported that little is known on issues such as the quality assurance and impact of coaches, and further suggested that one way of addressing these limitations is through focussing on the right coach specification and context for coaches (Yates, 2015b)

Research further indicates that the demands of development centres are particularly challenging for assessors and observers (Kolk et al., 2002; Robie, Osburn, Morris, Etchegaray, \& Adams, 2000; Woodruffe, 2000). The large amount of job-relevant behaviours elicited at the centre that needed to be observed, recorded and classified are cognitively demanding (Kolk et al., 2002; London, 2001; Robie et al., 2000; Shore, Thornton, \& Shore, 1990; Woodruffe, 2000). Within a CDC, the role of an observer extends to that of a coach because of added focus on coaching. Gaugler and Thornton (1989) stated that the cognitive demands placed on observers and assessors in DCs are even greater than the demands placed on assessors in assessment centres (ACs), and even greater on CDC assessors.

Despite this concern, very little evidence exists regarding the cognitive processes of observers (Hennessy, Mabey, \& Warr, 1998; Kolk et al., 2002) and competencies of coaches in general (Bono, Purvanova, Towler, \& Peterson, 2009), with no existing research on the cognitive processes of coaches in CDCs. This calls for an urgent need to explore the behaviours and competencies that allow observers and coaches to cope better with the complexity associated with the various tasks they engage in (Bycio, Alvares, \& Hahn, 1987; Passmore \& Fillery-Travis, 2011).

Ryan, Emmerling and Spencer (2009) indicate that competencies provide valuable insight into what the capabilities of a particular individual are. They define competencies as 'abilities related to motive and personality constructs that influence the frequency and intrinsic affective value associated with the execution of specific behaviours and cognitive-affective processes' (p. 860). Fletcher (1992, p. 7) refers to competencies as 'bundles of behaviour' required to deliver the desired

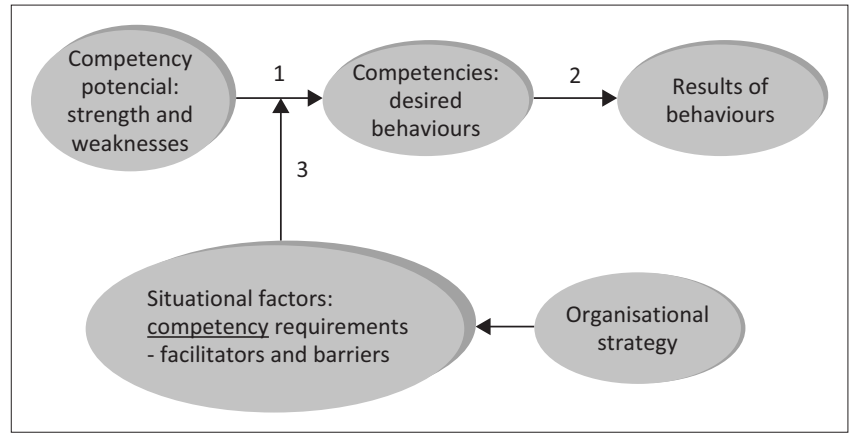

Source: Adapted from: SHL. (1994). The job analysis and competency design course training manual, p. 11, Pretoria: SHL.

FIGURE 1: The relationship between competency potential, competency requirements and competencies.

outcome. Emphasis is placed on the importance of behaviour in delivering the desired work outcomes, and focuses on the action or outcome that is exhibited (Markus, Thomas, \& Allpress, 2005; Theron, 2014). If coaches were to be selected according to the required competencies identified for that position, the cognitive demands inherent to their role could be dealt with greater ease and effectiveness.

A competency model will provide much needed guidance into the behavioural specification, skills and traits that are needed to perform as a CDC coach, as well as providing the overall validity of the centre. Current models, although useful to an extent, do not provide in-depth knowledge of what is needed. For example, the single-job competency model allows key job requirements to be identified and described. It specifies the behaviour required to yield optimal results in a given position. The 'one-size-fits-all' competency model approach identifies and describes desired competencies that are applicable for a wide range of jobs (Mansfield, 1996). Both these models merely specify behaviour that is observable on the surface.

Saville and Holdsworth (SHL) developed a competency framework providing a holistic depiction of competencies within the organisational context. Their framework conceptualises the inter-relationships between competency potential, competencies, results of behaviour (performance outcomes) and situational variables (see Figure 1) (Bartram, 2006).

Competency potential refers to the underlying dispositions that produce outcomes of observable behaviour (Heider, 1958 as cited in Ajzen, 2005). Ajzen (2005) describes competency potential as the personality traits and attitudes that a person possesses. Results of behaviour are defined as 'actual or intended outcomes of behaviour' (Bartram, 2006, p. 5). Theron (2014) adds that performance outcomes reflect the success of the individual's efforts in fulfilling the objectives for the task at hand. Situational variables can be described as external factors that often prevent competencies from delivering effective performance outcomes (Bailey, Bartram, \& Kurz, 2001; Campion \& Ployhart, 2013; Van der Bank, 2007). These variables may include aspects such as an organisation's climate or culture; working relationships and/or communication 
channels. By describing sets of behaviour in terms of the various layers of competency components, a better understanding of behaviour is enabled (Bartram, 2006).

By providing a structured and evidence-based framework that facilitates a more in-depth understanding of behaviour in the workplace (Bartram, 2006), this framework is deemed most appropriate for the purpose of this study.

To assist with the identification of CDC competencies, a thorough literature review was conducted. We used Academic Search Ultimate, Emerald Insight, ProQuest Central, PsycInfo, SpringerLink, SAGE journals, and Google Scholar and used keywords such as ACs, DCs, DACs, CDCs, coaches, competencies and competency frameworks. Six clusters consisting of 14 competencies could be identified (see Table 1). The first cluster of competencies is assessment, relating to the manner in which CDC coaches provide feedback to participants. Honesty was shown to be important in providing feedback regarding participants' strengths, development areas, effectiveness and performance levels (Appelbaum, Harel, \& Shapiro, 1998; Gettman, 2008; McCauley \& Van Velsor, 2004; Poteet \& Kudisch, 2003; Woodruffe, 2000). Exploratory behaviour is also needed to explore alternative forms of behaviour and to facilitate a non-threatening, learning environment for participants. Furthermore, openness to experience is necessary to be attentive towards participants' feelings and encourage open dialogue (Stelter, 2014; Woodruffe, 1990). Mutual responsiveness is also acknowledged as an important competency in order to encourage reflection (Gettman, 2008; Rider, 2002; Woodruffe, 2000). Relational attunement is additionally needed to encourage conversation and display empathy towards participants (Gettman, 2008; Stelter, 2014).

The second cluster of competencies is communication, which relates to the manner in which the CDC coach engages with the participant. Communication skills involve effective questioning and listening skills, the ability to support logical and convincing arguments to achieve a specific purpose (Brits, 2011), as well as the ability to convey threatening information in a manner that enhances the individual's understanding of a particular concept, whilst providing ongoing support; tailoring the conversation to the individual's unique context (Brown \& Bylund, 2008; Hobgood et al., 2002; Maguire \& Pitceathly, 2002). It is necessary that the CDC coach possesses all these components of communication skills.

The third cluster of competencies is challenge, the ability to utilise goal-oriented behaviour to challenge the participant to move outside their comfort zones in order to facilitate behavioural change and improved performance in a given job (Elliott, 2011).

Support is categorised as the fourth cluster of competencies. Through receiving ongoing support, participants are more likely to identify with the development needs raised and to persevere during challenging developmental experiences
TABLE 1: Proposed competencies for coaches in a coaching development centre identified from the literature review.

\begin{tabular}{ll}
\hline Competency cluster & Competency \\
\hline Assessment & $\begin{array}{l}\text { Honesty } \\
\text { Exploratory behaviour } \\
\text { Openness to experience } \\
\text { Mutual responsiveness } \\
\text { Relational attunement }\end{array}$ \\
\hline Communication & Communication skills \\
Challenge & $\begin{array}{l}\text { Goal orientation } \\
\text { Empowering behaviour }\end{array}$ \\
Support & $\begin{array}{l}\text { Emotionally supportive behaviour } \\
\text { Tactically supportive behaviour }\end{array}$ \\
Cultural competence & $\begin{array}{l}\text { Cultural self-awareness } \\
\text { Cultural sensitivity }\end{array}$ \\
Motivation & $\begin{array}{l}\text { Emotional control } \\
\text { Motivational reinforcement }\end{array}$ \\
\hline
\end{tabular}

that require change (McCauley \& Van Velsor, 2004; The British Psychological Society, 2003). Two competencies are necessary in this regard, namely, emotionally and tactically supportive behaviour. Emotionally supportive behaviour illustrates the coach's ability to display the necessary comfort and sympathy towards participants, whilst tactically supportive behaviour is needed to provide constructive advice and guide participants in achieving developmental goals (Gettman, 2008).

The fifth cluster of competencies is attributed to the fact that CDC coaches will be required to engage with participants that have diverse cultural backgrounds. For this, cultural selfawareness and sensitivity are necessary. This requires a coach to be mindful of the perceptions, mind sets and attitudes that may impede interactions with participants (American Psychological Association, 2003; Bennett \& Bennett, 2004; Waites, Macgowan, Pennell, Carlton-LaNey, \& Weil, 2004).

The sixth cluster of competencies is motivation. Participants need to believe that they possess the necessary capabilities to accomplish a particular goal. To motivate the participant to achieve their desired performance outcomes, the CDC coach needs to possess emotional control skills to maintain focus on the task at hand (Gettman, 2008; Kanfer \& Heggestad, 1997), as well as motivational reinforcement to improve participants' focus and perseverance (Christiansen \& Tett, 2013; Kanfer \& Heggestad, 1997). Table 1 summarises the proposed competency framework for coaches in a CDC that was established through the literature review.

\section{Goals of the study}

This study set out to explore the required competencies and formulate a competency framework for coaches working in a CDC.

\section{Method \\ Participants and setting}

Obtaining coaches working in a CDC was challenging. Currently there are very few CDC coaches, and they are almost all white people. The sample size for this study was therefore small, consisting of eight participants. The mean age of the participants was $46-55$ years and the mean job tenure was > than 11 years. 
TABLE 2: Examples of questions provided in the self-completed questionnaires. Number The desired competencies of coaches in a CDC

1. One of the core functions of a coach in a $C D C$ is to provide multiple points of feedback on simulation exercises (e.g. role-plays, presentations, in-baskets and group discussions) to improve participants' performance on the targeted dimensions. How important is it to provide honest feedback regarding participants' developmental areas in these exercises? - Not important at all

- Somewhat important

- Neutral

- Important

- Extremely important

2. In providing feedback on simulation exercises, how important is it to encourage collaborative dialogue with the participant?

- Not important at all

- Somewhat important

- Neutral

- Important

- Extremely important

3. What competencies do you consider are instrumental in effectively observing and evaluating the behavioural competencies in the various simulation exercises?

$\mathrm{CDC}$, coaching development centres.

TABLE 3: Examples of questions addressed in the semi-structured interviews: The competencies of coaches in a CDC.

\begin{tabular}{ll}
\hline Core question & Probing questions \\
\hline $\begin{array}{l}\text { 1. What are the main challenges } \\
\text { that you experience as a coach }\end{array}$ & $\begin{array}{l}\text { - What competencies do you think are } \\
\text { important in order to effectively deal } \\
\text { operating in the context of a CDC? } \\
\text { - With the challenges you just mentioned? } \\
\text { - Would you say that these competencies } \\
\text { are unique to the context of a CDC? } \\
\text { - [If participants responded no to previous } \\
\text { question:] What competencies would you } \\
\text { say are unique to the context of a CDC? } \\
\text { - [If participants responded yes to previous } \\
\text { question:] In what way are these } \\
\text { competencies unique to the context of a }\end{array}$ \\
$\begin{array}{ll}\text { CDC? } \\
\text { 2. What developmental areas have }\end{array}$ \\
$\begin{array}{ll}\text { you identified for yourself as a } \\
\text { coach in the context of a CDC? }\end{array}$ & $\begin{array}{l}\text { participants in a CDC would improve if } \\
\text { you successfully developed these areas? }\end{array}$ \\
\hline
\end{tabular}

$\mathrm{CDC}$, coaching development centres.

The majority of the coaches had completed coaching diplomas. The expert panel who validated the competency framework consisted of five participants, with a mean age of 46-55 years, and had a mean job tenure of $>24$ years.

\section{Measures}

Self-completed questionnaires were administered first, followed by semi-structured interviews. To verify the competency framework, a Delphi technique was administered to an expert panel.

\section{Procedure}

To validate and expand the preliminary competency framework outlined in Table 1, a phenomenological research approach was followed, along with a qualitative exploratory approach. Appropriate permission and consent were obtained and all ethical standards were adhered to in the study. Participants were required to complete a questionnaire with open and closed questions where they were asked to rank the importance of the competencies. A thorough literature review was conducted to identify competencies for coaches from a theoretical and empirical perspective. The identified competencies formed the basis of the proposed competency framework. A self-completed questionnaire containing open and closed questions was constructed to allow participants to rate each identified competency in the order of importance $(1=$ not at all important and $5=$ extremely important). This enabled the differentiation between core and secondary competencies. Examples of questions are presented in Tables 2 and 3.

The three open-ended questions focused on the uniqueness of the CDC context and allowed respondents to freely provide detailed and contextual information. It was also important to determine whether the coaches working in CDCs perceived differences between the competencies of normal coaches and coaches in a CDC environment. In the follow-up interviews, the experiences of the coaches in CDCs were explored in more detail, with an additional focus to determine whether the competencies of normal coaches working in development centres differed from that of coaches working in CDCs. After each step of the data collection, the proposed competency framework was refined. Finally, the input of the experts was elicited to validate the proposed competency framework by utilising the Delphi technique. The Delphi technique served as a final phase to validate and refine the competency framework. By using subject matter experts in the field to scrutinise the findings, further validation is provided (Habibi, Sarafrazi, \& Izadyar, 2014; Strasser, London, \& Kortenbout, 2005). In this study, four questions were posed to the experts, in which they had: (1) to rank the competencies in the order of importance, (2) to rank the five most important and five least important competencies, (3) to identify competencies that should not form part of the competency framework and (4) to include any other additional competencies not listed in the competency framework.

\section{Data analysis}

The information obtained in all three sets of data was analysed and interpreted from an interpretive research paradigm using a directed approach to content analysis. A directed approach of content analysis is used when existing theory regarding a phenomenon is incomplete or can benefit from additional research. Codes were allocated to all occurrences of a theme identified in the data. In the three rounds of data collection, specific attention was given to overlapping codes, how it was presented and how frequently the response was given. Themes not falling into the existing categories received new codes until all themes were identified. A directed approach to content analysis can also be to present descriptive evidence, using the rank order of comparisons of frequency of codes. Participants were required to rank the level of importance of each competency included in the preliminary competency framework according to a five-point rating scale. This allowed the formulation of a frequency table, depicting the average importance of each competency as rated by all participants. Core competencies could then be differentiated from secondary competencies.

In the final step, a Delphi technique was used. The input and consensus from five expert coaches (who are not part of the original group) in the field of CDCs were obtained. The purpose was to provide an enriched understanding of the competencies of coaches in a CDC. Using the same rating scale as with the self-completed questionnaires, each competency's level of importance was established and organised, clearly demarcating core and secondary 
competencies for a CDC coach. Two iterations of the Delphi questionnaire were conducted, with a majority consensus obtained in both iterations. The second iteration was selected to inform the final validation and development of the comprehensive competency framework for coaches in a CDC.

\section{Ethical considerations}

Ms B. Slabbert (former Venter) presented her proposal in April 2016 to a proposal panel of the Department of Industrial Psychology and People Management, University of Johannesburg. The proposal was accepted and ethical clearance was given at the departmental level as part of this proposal committee. At the time, ethical clearance numbers were not awarded.

\section{Results}

Table 4 outlines the comprehensive competency framework for coaches in a CDC, developed through a literature review and three phases of data collection. The final competency framework for CDC coaches included a total of 25 competencies. Of these 25 competencies, 14 competencies were revealed to be core competencies and 11 were secondary competencies. Twelve additional competencies emerged from the data, which were initially not included in the preliminary competency framework developed through academic theorising. These include people-orientation, AC knowledge,

TABLE 4: The comprehensive competency framework for coaches in a coaching development centre.

\begin{tabular}{ll}
\hline $\begin{array}{l}\text { The competencies of a coach in a CDC } \\
\text { (competency framework) }\end{array}$ & Average ranking \\
\hline Core competencies & \\
1. Communication skills & 4.9 \\
2. Empowering behaviour & 4.9 \\
3. Honesty & 4.8 \\
4. Openness to experience & 4.8 \\
5. People orientation & 4.6 \\
6. Assessment centre knowledge & 4.6 \\
7. The ability to work within the framework of the CDC & 4.5 \\
8. Positive regard & 4.5 \\
9. Relational attunement & 4.5 \\
10. Interpersonal sensitivity & 4.3 \\
11. Analytical thinking skills & 4.3 \\
12. Tactically supportive behaviour & 4.3 \\
13. Flexibility & 4.3 \\
14. Emotional control skills & 4.2 \\
Secondary competencies & \\
15. Mutual responsiveness & 3.5 \\
16. Exploratory behaviour & 3.0 \\
17. Goal orientation & 3.5 \\
18. Objectivity & 3.5 \\
19. Energy/drive & 3.0 \\
20. Emotionally supportive behaviour & 4.0 \\
21. Time management skills & 3.0 \\
22. Concentration skills & 3.8 \\
23. Cultural self-awareness & 3.2 \\
24. Conscientiousness & \\
25. Motivational reinforcement & \\
\hline CDC, coaching development centres. & \\
\hline
\end{tabular}

CDC, coaching development centres. the ability to work within the framework of a CDC, positive regard, interpersonal sensitivity, analytical thinking skills, flexibility, objectivity, time management skills, energy or drive, conscientiousness and concentration of skills.

\section{Discussion}

The results supported the proposed competency framework for coaches working in a CDC to a large degree but also included additional competencies that were identified by coaches and experts working in CDCs. According to participants' responses, CDC coaches are confronted with greater role demands than that of a general coach, as well as an assessor and observer at an AC and DAC, respectively. These demands include the added time pressure of the centre; the constrained time available with participants; the unique framework, procedures, deliverables and processes; the additional documentation to be completed; the additional assessor competencies needed, such as behavioural observations, recordings and classifications that need to be done; the greater amount of energy required to persevere; and the knowledge and experience required for the CDC method.

Table 4 represents the final competency framework for coaches in a CDC. It depicts 25 desired competencies that enable CDC coaches to deliver optimal performance outcomes. Of these 25 competencies, 13 emerged in the preliminary literature review. The remaining 12 competencies newly emerged in the data. The final validated competencies are briefly discussed below.

\section{Communication skills}

Communication skills were rated by the panel of experts as the most important competency. Various researchers stress how important communication is in the coaching relationship, in creating positive change, clarification of issues and increasing understanding of development needs (Gray, 2006; Kombarakaran, Yang, Baker, \& Fernandes, 2008; Lemasa, 2016). Participants also stressed the importance of how information is relayed. Information shared in a non-directive and practical manner encourages coachees to take ownership of their learning process (Barnett, 1995; Baron \& Morin, 2009; Lemasa, 2016).

\section{Empowering behaviour}

The demanding nature of a CDC was reiterated several times. According to participants' responses, the pressured time frames and the framework of the programmes heighten stress and frustration levels. The various demands placed on CDC coaches cannot be eliminated, as they are inherent to the centre. However, by managing these emotions and maintaining control over them, leaders are more likely to establish an environment that is marked by trust and fairness (Goleman, 2003; Riggio \& Lee, 2007). Participants also emphasised the importance of recognising and regulating one's emotions and taking care in avoiding the spill-over effect to other coaches. A coach is not only responsible for recognising his or her own emotional behaviour, but also 
needs to be sensitive towards the feelings and emotions of the coachee (Goldfried \& Davison, 1976; Seligman, 1991). This is aligned with Goleman's model of emotional intelligence that indicates how self-awareness, relationship management, social awareness and self-management help in achieving successful performance.

\section{Honesty}

Participants highlighted the importance of honesty in a nondirective approach. Feedback should focus on what the coachee's strengths and what he or she is doing well. When feedback is too direct and negative, it inhibits the learning performance.

\section{Openness to experience}

This competency is another important requirement for coaches in CDCs in order to encourage open and collaborative dialogue. Participants stressed that one of the main objectives of a coach in a CDC is to stimulate insight and self-awareness amongst coachees. As the timeframe in which this can happen is rather short, the coach needs to be competent in facilitating this process.

\section{People orientation}

By nature, coaches work with people for extended periods of time. To ensure effective interaction, a good relationship with the coachee is vital. The role of the coach has also transformed from being an expert to that of a thought partner, together with whom the coachee can come up with solutions (Eggers \& Clark, 2000). This approach builds trust with the coachee and promotes accepting responsibility for one's own learning.

Assessment centre knowledge: Coaching development centres coaches must understand the basic principles of the AC method. This includes an understanding of how to effectively observe, classify, record and evaluate the behavioural dimensions; understand the selected assessment dimensions and how it relates to performance and knowledge, and mastery of the assessment techniques utilised in the centre (ACSG, 2015; Ballantyne \& Povah, 2004). Assessment centre knowledge provides the foundation for being an effective CDC coach (ACSG, 2015; Griffiths \& Allen, 1987).

The ability to work within the framework of a coaching development centres: An AC operates according to a specific framework with unique processes, procedures and techniques used (Ballantyne \& Povah, 2004). This includes a large number of dimensions to be assessed, different assessment techniques, the use of specific evaluating and rating procedures of the centre, and engaging in objective role-playing during interactive exercises - all to be completed within a specific time limit (ACSG, 2015). These demands place added strain on the assessor, which may increase the anxiety and frustration levels. It is important that the CDC coach is acquainted with and experienced in each of these role requirements in order to provide greater ease and effectiveness in the delivery of performance.

\section{Positive regard}

Rogers (1959) defined positive regard as an unconditional source of warm acceptance towards a client. Effective coaching relies on the coach's ability to establish an environment marked by unconditional positive regard, in which the coachee feels heard, appreciated and not judged (Eggers \& Clark, 2000). Although maintaining a positive regard is important, the coach still needs to remain as objective as possible (Ballantyne \& Povah, 2004).

\section{Relational attunement}

Both participants and experts highlighted that a positive relationship between the coach and coachee is essential for achieving behavioural outcomes. Coaches in a CDC need to be relationally attuned to coachees, to establish a connection within a short amount of time and to build a positive relationship marked by openness, empathy and non-judgement. This helps creating a safe environment conducive to learning and change (Bluckert, 2005; Brotman, Liberi, \& Wasylyshyn, 1998; O'Flaherty \& Everson, 2005).

Interpersonal sensitivity: This competency is necessary in order for CDC coaches to relate effectively to all types of participants, and to establish appropriate rapport (Dingman, 2004). It is especially important that they pick up the nonverbal cues of coachees in their evaluation of their behavioural competencies in the various simulation exercises.

Analytical thinking: This competency refers to the ability to think in a logical manner, unpack complex problems and recognise a cause-and-effect relationship (Ballantyne \& Povah, 2004; Lithner, 2008). It will allow the coach to be systematic in his or her approach, allowing feedback to be substantiated. By substantiating arguments, feedback is more likely to be accepted by participants (Tucker, 1997).

\section{Goal orientation and tactically supportive behaviour}

These two competencies are discussed jointly as they have similar implications in the competency framework. Both support a more directive and instructional approach. The key outcomes of a CDC are the formulation of a development plan. A practical, step-by-step approach with clear guidelines will help to achieve specific behavioural outcomes quicker, result in long-term behavioural change and the development of one's own solutions (Ives, 2008; McCarthy \& Milner, 2013).

Flexibility: A coach in a CDC is required to work with different individuals that have different development needs and learning styles (Ballantyne \& Povah, 2004; Kiel, Rimmer, Williams, \& Doyle, 1996). As a result, flexibility is needed to adapt to the different participants and the situational demands the CDC may deliver. By possessing sufficient 
flexibility, CDC coaches are better able to deal with these challenges in the most appropriate manner possible.

\section{Emotional control skills}

Because of the inherent demanding nature of a CDC, pressured time frames and the structure of the programmes, coaches have to deal with heightened stress and frustration levels. Being aware of and being able to manage your emotions is essential for creating the right environment characterised by trust and fairness.

\section{Mutual responsiveness}

The typical duration of a CDC programme is 3 days, which provides a very short time for any change or development to occur. To maximise development outcomes, coaches need to be reflective as this stimulates the necessary insight and motivation to sustain development and improvement beyond the duration of the CDC. A reflective coach provides an inviting platform for the coachee to also be reflective and become self-sufficient (Plunkett, Egan, \& Garza, 2004).

\section{Exploratory behaviour}

Coaching approaches are usually characterised in terms of two dimensions: being either directive or non-directive. Nondirective approaches are instructional and goal-oriented and rely on questioning and feedback to enhance the coach's ability to explore together with the coachee what options are available (Bond \& Seneque, 2012; Ives, 2008; Parsloe, 2009).

Impartiality: Coaches who favour some individuals over others exert more effort towards enhancing their development success, disadvantaging other participants. This distorts participants' performance, leading to unfavourable outcomes. Coaches at a CDC must remain impartial in their assessments of behaviour and must ensure that they provide sound, objective judgement that is free from bias.

Energy and drive: These are additionally necessary to withstand the exhausting nature of the CDC process. Coaches must be able to proactively manage their energy levels and plan appropriately to ensure that sustainable levels of energy are exerted. This will ensure that the CDC coach is able to provide his or her undivided attention to the participants throughout the duration of the centre (Bossons, Kourdi, \& Sartain, 2013).

\section{Emotionally supportive behaviour}

Participants indicated the importance of emotional support within the CDC context. The programmes are emotionally and cognitively exhausting. When coachees feel emotionally supported and understood, they feel more encouraged to reveal their vulnerabilities, explore, take risks and take responsibility for their development process (Bluckert, 2005).

Time management: Specific tasks need to be completed within clearly defined time limits. The duration of each discussion needs to be carefully considered in terms of the total amount of time that is available (Ballantyne \& Povah, 2004). Should a coach fail to do so, all the necessary discussion points may not have been covered with the participant in time for the next simulation exercise. This may leave the participant unsatisfactorily prepared for the exercise to follow, constraining the participant's overall performance. In addition, documentation also needs to be completed. To ensure that all the performance demands are met within the prescribed amount of time, a CDC coach needs to be highly time-conscious.

Concentration: In addition to the highly cognitive demanding nature of the role of a CDC coach (Kolk et al., 2002; London, 2001; Robie et al., 2000; Woodruffe, 2000), the centre typically consists of a full day of behavioural activities, adding to its overall intensity. To ensure that the coach at the CDC is able to focus all attention on the individual being assessed and the tasks to be completed for the entire duration of the centre, concentration skills emerged as a key competency.

\section{Cultural competence (cultural self-awareness and cultural sensitivity)}

Both cultural self-sensitivity and cultural awareness were initially rated as one the most important competencies. Interestingly enough, participants did not elaborate on this at all. During the validation phase, experts rated cultural sensitivity as being neutrally important and cultural awareness as not important at all. This was not expected. A closer investigation of the phrasing revealed that cultural self-awareness leaned more towards being aware and mindful of one's own perspectives and world views, where cultural sensitivity focused on understanding different cultural contexts. Another possible reason for this can be argued to be the result of the current workforce profile at top management level, which is mainly white (Republic of South Africa, 2015). Because CDCs mostly work with participants at top management level, it could be possible that a need for cultural sensitivity is not too pronounced owing to the workforce profile that is not yet representative of a culturally diverse nation. It was also clear that there is a shortage of coaches representing different cultural groups, as 12 of the 13 research participants were white people. Because of the changing demographics of the workforce, it is reasonable to expect that this situation will and should change in the future. Cultural sensitivity is also not just limited to race. Being culturally sensitive requires the knowledge of, understanding of and respect for others' beliefs, emotions, values, background, symbolism and biases (Kubokawa \& Ottaway, 2009; Miller, Engelbrecht, Wang, \& Tsudaka, 2020).

Conscientiousness: Because of the highly structured framework of the centre and the required accuracy of tasks, CDC coaches need to be sufficiently detail-orientated and organised to perform effectively. They should be simultaneously mindful of the time pressures inherent to their role (Yeo \& Neal, 2004). Since extreme levels of conscientious may result in more time invested in the 
completion of tasks, moderate levels of conscientious were found to be optimal for a CDC coach. This will ensure that the necessary details of tasks are attended to, whilst still comfortably adhering to the time limits of the centre.

\section{Motivational reinforcement}

The last important competency emphasised that the desire to success must rest with the coachee. As adult learners who are mostly at management and senior management levels, a desire to improve and succeed must already be present before they embark on the CDC process. The coach can then continue to build resilience and reinforce this sense of motivation by being supportive and nurturing (Baumeister et al., 2006, cited in Grant, Curtayne, \& Burton, 2009).

Finally, based on the feedback received from the participants and the expert panel, one can conclude that the role of coaches working in CDCs is unique and demanding in many respects. Coaches work with participants on a one-on-one basis. In a very short length of time, rapport must be built, development plans must be formalised and various discussions must take place to focus on improvements against certain behavioural outcomes and desired performance results. To succeed in such a high pressured environment, a unique set of competencies is needed.

\section{Limitations and implications of the study}

Certain limitations were noted. Since the desired competencies of CDC coaches were explored only from the coaches' perspectives, the perspectives of the coachee and other key role-players involved in the centre were not explored. It may be argued that the study does not provide an all-inclusive representation of the desired competencies of coaches in a CDC.

Coaching development centres are a relatively recent emergence with limited research available. This study was predominantly approached from the perspective of an assessor or observer, or a coach working in a CDC. Finding participants who have sufficient experience and expertise in the field proved to be difficult. There is also a huge shortage in experienced coaches working in CDCs from other cultural groups. Lastly, the situational factors existing between the competency-performance outcome relationships were not considered as part of this study. By not recognising these influencing factors, only a partial competency model for coaches in a CDC could be provided.

In terms of practical applications, this study contributes to the understanding of the unique behavioural demands associated with coaches operating in the context of a CDC. It provides a conceptual and practical framework of what competencies are needed to work successfully and effectively as a coach in a CDC.
Furthermore, the only best practice guidelines currently available are for the use of the AC method. These guidelines do not address CDCs, nor do they address the role of the coach at the CDC. The field of CDCs could benefit from the design of best practice guidelines specifically for the use of the CDC method, the selection of CDC coaches, as well as the training that should be imparted. This would ensure that all CDCs extract optimum performance excellence from coaches operating in this context, and in doing so enhance the success of the CDC field.

The proposed competency framework may be applied in practice to increase awareness of the performance and behavioural expectations of the CDC coach, benefiting the CDC participant, the CDC as a whole and the host organisation. By applying this framework in practice, CDC participants would receive coaching from the best possible candidates for the role, enhancing the participant's possibility of developing the desired behaviours. By optimising the participant's development success, the effectiveness of the CDC would be increased. This in turn, would enhance the attractiveness of the CDC method, encouraging greater usage and greater development of the field as a whole. By ensuring that the development of participants is maximised, greater value would be injected back into the organisation, thereby contributing to the organisation's sustainable, competitive advantage.

This framework could further be used as a behavioural guideline, whereby coaches at a CDC could map their own behaviour to that which is expected or desired. This would allow CDC coaches to easily identify any behavioural discrepancies and use it to inform personal developmental areas.

It is recommended to expand the competency framework developed in this study to include the person-centred attributes and situational variables that moderate the competency-performance outcome relationship. A fully fledged competency framework that includes all of these variables would facilitate a coherent understanding of CDC coaching excellence, both on the behavioural and performance outcome level. This would contribute a significant amount of value to the field of CDCs.

\section{Conclusion}

In summary, this study recognised that no clear framework exists explicating the competencies that allow coaches in a CDC to cope better with the demanding tasks they engage in. In response to this need, this study set out to explore the competencies of coaches at a CDC that would facilitate greater ease and effectiveness in performance. Because research in the field of CDCs is yet limited, with no existing research on the competencies of CDCs, the gaps existing in the literature could be addressed through this study and a contribution could be made to the body of knowledge in the coaching discipline, particularly within the context of CDCs. 
This unique competency framework developed for coaches at a CDC informs the unique challenges faced by coaches at a CDC, and the competencies needed to effectively meet these challenges.

\section{Acknowledgements Competing interests}

The authors have declared that no competing interests exist.

\section{Authors' contributions}

B.S. collected the data and completed a mini dissertation on the topic. C.H. wrote the article based on the results of the study and a draft article was submitted by Ms B. Slabbert.

\section{Funding information}

This research received no specific grant from any funding agency in the public, commercial or not-for-profit sectors.

\section{Data availability}

The data that support the findings of this study are available from the corresponding author, C.H., upon reasonable request.

\section{Disclaimer}

The views and opinions expressed in this article are those of the authors and do not reflect the official position of any affiliated agencies of the authors

\section{References}

Ajzen, I. (2005). Attitudes, personality, and behavior (2nd ed.). Milton-Keynes: Open University Press/McGraw-Hill.

American Psychological Association. (2003). Guidelines on multicultural education, training, research, practice, and organizational change for psychologists. The American Psychologist, 58(5), 377. https://doi.org/10.1037/0003-066X 58.5.377

Appelbaum, S.H., Harel, V., \& Shapiro, B. (1998). The developmental assessment centre: The next generation. Career Development International, 3(1), 5-12. https://doi.org/10.1108/13620439810368574

Assessment Centre Study Group (ACSG). (2015). Best practice guidelines for the use of the assessment centre method in South Africa (5th ed.). Stellenbosch: Assessment Centre Study Group (ACSG). Retrieved from http:// www.acsg.co.za

Bailey, R., Bartram, D., \& Kurz, R. (2001). Cracking competencies: Development of the SHL competency framework. Paper presented at the British Psychological Society (BPS) Centenary Conference, Glasgow.

Ballantyne, I., \& Povah, N. (2004). Assessment and development centres. Aldershot, Hants: Gower Publishing.

Barnett, B.G. (1995). Developing reflection and expertise: Can mentors make the difference? Journal of Educational Administration, 33(5), 45-59. https://doi. difference? Journal of Educational
org/10.1108/09578239510098527

Baron, L., \& Morin, L. (2009). The coach-coachee relationship in executive coaching: A field study. Human Resource Development Quarterly, 20(1), 85-106. https://doi. org/10.1002/hrdq.20009

Bartram, D. (2006). The SHL universal competency framework. Surrey: SHL White Paper.

Bennett, J.M., \& Bennett, M.J. (2004). An integrative approach to global and domestic diversity. In Handbook of intercultural training (pp. 147-165). Thousand Oaks, CA Sage Publications.

Bluckert, P. (2005). Critical factors in executive coaching: The coaching relationship. Industrial and Commercial Training, 37(7), 336-340. https://doi.org/10.1108/ 00197850510626785

Bond, C., \& Seneque, M. (2012). Conceptualizing coaching as an approach to management and organizational development. Journal of Management Development, 32(1), 57-72. https://doi.org/10.1108/02621711311287026
Bono, J., Purvanova, R., Towler, A., \& Peterson, D.B. (2009). Survey of executive coach practices. Personnel Psychology, 62(2), 361-404. https://doi.org/10.1111/j. 1744-6570.2009.01142.x

Bossons, P., Kourdi, J., \& Sartain, D. (2013). Coaching essentials: Practical, proven techniques for world-class executive coaching. London: Bloomsbury.

Brits, N. (2011). An explorative investigation into the construct validity of a development assessment centre (Doctoral dissertation, University of Stellenbosch).

Brotman, L.E., Liberi, W.P., \& Wasylyshyn, K.M. (1998). Executive coaching: The need for standards of competence. Consulting Psychology Journal: Practice and Research, 50(1), 40. https://doi.org/10.1037/1061-4087.50.1.40

Brown, R.F., \& Bylund, C.L. (2008). Communication skills training: Describing a new conceptual model. Academic Medicine, 83(1), 37-44. https://doi.org/10.1097/ ACM.0b013e31815c631e

Bycio, P., Alvares, K.M., \& Hahn, J. (1987). Situational specificity in assessment center ratings: A confirmatory factor analysis. Journal of Applied Psychology, 72(3), 463474. https://doi.org/10.1037/0021-9010.72.3.463

Campion, M.C., \& Ployhart, R.E. (2013). Assessing personality with situational judgment measures: Interactionist psychology operationalized. In N.D. Christiansen \& R.P. Tett (Eds.), Handbook of personality at work (pp. 439-456). New York, NY: Routledge.

Christiansen, N., \& Tett, R. (2013). Handbook of personality at work. New York, NY Routledge.

Dingman, M.E. (2004). The effects of executive coaching on job related attitudes (Unpublished dissertation). Regents University.

Eggers, J.H., \& Clark, D. (2000). Executive coaching that wins. Ivey Business Journal, 65(1), 66-70.

Elliott, R. (2011). Utilizing evidence-based leadership theories in coaching for leadership development: Towards a comprehensive integrating conceptual framework. International Coaching Psychology Review, 6(1), 46-70.

Fletcher, S. (1992). Competence-based assessment techniques. London: Kogan Page.

Gaugler, B.B., \& Thornton, G.C. (1989). Number of assessment center dimensions as a determinant of assessor accuracy. Journal of Applied Psychology, 74(4), 611-618. https://doi.org/10.1037/0021-9010.74.4.611

Gettman, H.J. (2008). Executive coaching as a developmental experience: A framework and measure of coaching dimensions (Doctoral Dissertation, University of Maryland, College Park, MD). Retrieved from ProQuest Dissertations and Theses database. (UMI No 3324934)

Goldfried, M.R., \& Davison, G.C. (1976). Clinical behavior therapy. New York, NY: Holt Rinehart.

Goleman, D. (2003). What makes a leader? In L.W. Porter, H.L. Angle, \& R.W. Allen (Eds.), Organizational influence processes (pp. 229-241). New York: ME Sharpe.

Grant, A.M., Curtayne, L., \& Burton, G. (2009). Executive coaching enhances goa attainment, resilience and workplace well-being: A randomised controlled study. The Journal of Positive Psychology, 4(5), 396-407. https://doi.org/10.1080/ 17439760902992456

Gray, D.E. (2006). Executive coaching: Towards a dynamic alliance of psychotherapy and transformative learning processes. Management Learning, 37(4), 475-497. https://doi.org/10.1177/1350507606070221

Griffiths, P., \& Allen, B. (1987). Assessment centres: Breaking with tradition. Journal of Management Development, 6(1), 18-29. https://doi.org/10.1108/eb051632

Habibi, A., Sarafrazi, A., \& Izadyar, S. (2014). Delphi technique theoretical framework in qualitative research. The International Journal of Engineering and Science, 3(4), 8-13.

Hennessy, J., Mabey, B., \& Warr, P. (1998). Assessment centre observation procedures: An experimental comparison of traditional, checklist and coding methods International Journal of Selection and Assessment, 6(4), 222-231. https://doi. org/10.1111/1468-2389.00093

Hobgood, C.D., Riviello, R.J., Jouriles, N., \& Hamilton, G. (2002). Assessment of communication and interpersonal skills competencies. Academic Emergency Medicine, 9(11), 1257-1269. https://doi.org/10.1197/aemj.9.11.1257

Ives, Y. (2008). What is 'coaching'? An exploration of conflicting paradigms. International Journal of Evidence Based Coaching and Mentoring, 6(2), 100-113.

Kanfer, R., \& Heggestad, E.D. (1997). Motivation traits and skills: A person-centered approach to work motivation. Research in Organizational Behavior, 19, 1-56.

Kiel, F., Rimmer, E., Williams, K., \& Doyle, M. (1996). Coaching at the top. Consulting Psychology Journal: Practice and Research, 48(2), 67. https://doi.org/10.1037/ 1061-4087.48.2.67

Kolk, N.J., Born, M.P., Van Der Flier, H., \& Olman, J.M. (2002). Assessment center procedures: Cognitive load during the observation phase. International Journal of Selection and Assessment, 10(4), 271-278. https://doi.org/10.1111/14682389.00217

Kombarakaran, F.A., Yang, J.A., Baker, M.N., \& Fernandes, P.B. (2008). Executive coaching: It works! Consulting Psychology Journal: Practice and Research, 60(1), 78. https://doi.org/10.1037/1065-9293.60.1.78

Kubokawa, A., \& Ottaway, A. (2009). Positive psychology and cultural sensitivity: A review of literature. Graduate Journal of Counselling Psychology, 1(2), 130-138.

Lemasa. (2016). Coaching development centres. Retrieved from www.lemasa.co.za

Lievens, F., \& Thornton, G.C. III (2005). Assessment centers: recent developments in practice and research. In A. Evers, O. Smit-Voskuijl, \& N. Anderson (Eds.), Handbook of selection (pp. 243-264). Blackwell Publishing, Hoboken, NJ.

Lithner, J. (2008). A research framework for creative and imitative reasoning. Educational Studies in Mathematics, 67(3), 255-276. https://doi.org/10.1007/ s10649-007-9104-2 
London, M. (2001). How people evaluate others in organizations. London: Lawrence Erlbaum Associates.

Maguire, P., \& Pitceathly, C. (2002). Key communication skills and how to acquire them. British Medical Journal, 325(7366), 697. https://doi.org/10.1136/ bmj.325.7366.697

Mansfield, R.S. (1996). Building competency models: Approaches for HR professionals. Human Resource Management, 35(1), 7. https://doi.org/10.1002/(SICI)1099 050X(199621)35:1\%3C7::AID-HRM1\%3E3.0.CO;2-2

Markus, L., Thomas, H.C., \& Allpress, K. (2005). Confounded by competencies? An evaluation of the evolution and use of competency models. New Zealand Journal of Psychology, 34(2), 117.

McCarthy, G., \& Milner, J. (2013). Managerial coaching: Challenges, opportunities and training. Journal of Management Development, 32(7), 768-779. https://doi. org/10.1108/JMD-11-2011-0113

McCauley, C.D., \& Van Velsor, E. (Eds.). (2004). The center for creative leadership handbook of leadership development (Vol. 29). New York, NY: John Wiley \& Sons.

Miller, J.G., Engelbrecht, J., Wang, Z., \& Tsudaka, G. (2020). Toward greater cultural sensitivity in development psychology. Applied Development Science, 25(1), 1-13. https://doi.org/10.1080/10888691.2020.1789348

O'Flaherty, C., \& Everson, J. (2005). Coaching in leadership development. Brain-based executive education. Johannesburg: Knowres.

Parsloe, E. (2009). Coaching and mentoring: Practical conversations to improve learning. London: Kogan Page.

Passmore, J., \& Fillery-Travis, A. (2011). A critical review of executive coaching research: A decade of progress and what's to come. Coaching: An International Journal of Theory, Research and Practice, 4(2), 70-88. https://doi.org/10.1080/17 521882.2011.596484

Plunkett, B.L., Egan, T.M., \& Garza, M. (2004). Current status of executive coaching interventions as identified by selected consultants to multinational organizations. In Academy of Human Resource Development 2004 Conference Proceedings, Bowling Green, OH: Academy of Human Resource Development (AHRD). pp. 18-25.

Poteet, M.L., \& Kudisch, J.D. (2003). Straight from the horses mouth: Strategies for increasing feedback acceptance. In 31st International Congress on Assessment Center Methods, Atlanta, GA.

Republic of South Africa. (2015). Commission for employment equity annual report Pretoria: Department of Labour.

Rider, L. (2002). Coaching as a strategic intervention. Industrial and Commercial Training, 34(6), 233-236. https://doi.org/10.1108/00197850210442476

Riggio, R.E., \& Lee, J. (2007). Emotional and interpersonal competencies and leader development. Human Resource Management Review, 17(4), 418-426. https:// doi.org/10.1016/j.hrmr.2007.08.008

Robie, C., Osburn, H.G., Morris, M.A., Etchegaray, J.M., \& Adams, K.A. (2000). Effects of the rating process on the construct validity of assessment center dimension
evaluations. Human Performance, 13(4), 355-370. https://doi.org/10.1207/ evaluations. Human 2

Rogers, C.R. (1959). A theory of therapy, personality, and interpersonal relationships as developed in the client-centered framework. Reprinted in $\mathrm{H}$. Kirschenbaum and V. Henderson (Eds.), The Carl Rogers reader (1989). Boston, MA: Houghton Mifflin.
Rupp, D.E., Gibbons, A.M., Baldwin, A.M., Snyder, L.A., Spain, S.M., Woo, S.E., ... Kim, M. (2006). An initial validation of developmental assessment centers as accurate assessments and effective training interventions. The Psychologist-Manager Journal, 9(2), 171. https://doi.org/10.1207/s15503461tpmj0902_7

Ryan, G., Emmerling, R.J., \& Spencer, L.M. (2009). Distinguishing high-performing European executives: The role of emotional, social and cognitive competencies. Journal of Management Development, 28(9), 859-875. https://doi. org/10.1108/02621710910987692

Seligman, M.P. (1991). Learned optimism. New York, NY: AA Knopf.

SHL. (1994). The job analysis and competency design course training manual, p. 11, Pretoria: SHL.

Shore, T.H., Thornton, G.C., \& Shore, L.M. (1990). Construct validity of two categories of assessment center dimension ratings. Personnel Psychology, 43(1), 101-114. $\mathrm{https} / / /$ doi.org/10.1111/j.1744-6570.1990.tb02008.x

Stelter, R. (2014). Third-generation coaching: Reconstructing dialogues through collaborative practice and a focus on values. International Coaching Psychology Review, 9(1), 51-66.

Strasser, S., London, L., \& Kortenbout, E. (2005). Developing a competence framework and evaluation tool for primary care nursing in South Africa. Education for Health, 18(2), 133-144. https://doi.org/10.1080/13576280500145615

The British Psychological Society. (2003). Design, implementation and evaluation of assessment and development centres: Best practice guidelines. Leicester: Psychological Testing Centre. Retrieved from www.psychtesting.org.uk

Theron, C.C. (2014). Psychometrics, measurement theory, test construction and decision-making (Unpublished class notes (Industrial Psychology 776)), University of Stellenbosch.

Tucker, L. (1997). The evaluation of a management development centre (Unpublished Master's dissertation). University of South Africa, Pretoria.

Van der Bank, F. (2007). The development and validation of a partial competency model for branch managers in the clothing retail industry (Unpublished Master's thesis). Stellenbosch University, Stellenbosch.

Yates, K. (2015a). Managing, tracking and evaluating coaching part 1: Where are you now? Industrial and Commercial Training, 47(1), 36-41. https://doi.org/10.1108/ ICT-08-2014-0057

Yates, K. (2015b). Managing, tracking and evaluating coaching part 2: Where could you be? Industrial and Commercial Training, 47(2), 95-98. https://doi. org/10.1108/ICT-08-2014-0058

Yeo, G.B., \& Neal, A. (2004). A multilevel analysis of effort, practice, and performance: Effects; of ability, conscientiousness, and goal orientation. Journal of Applied Psychology, 89(2), 231. https://doi.org/10.1037/0021-9010.89.2.231

Waites, C., Macgowan, M.J., Pennell, J., Carlton-LaNey, I., \& Weil, M. (2004). Increasing the cultural responsiveness of family group conferencing. Social Work, 49(2) 291-300. https://doi.org/10.1093/sw/49.2.291

Woodruffe, C. (1990) Assessment centres: Identifying and developing competence. London: Institute of Personnel Management.

Woodruffe, C. (2000). Development and assessment centres: Identifying and assessing competence. London: CIPD Publishing. 